\title{
Whole body potassium and total exchangeable potassium in elderly patients with cardiac failure
}

\author{
MICHAEL LYE AND BARRY WINSTON \\ From the Department of Geriatric Medicine, University of Manchester, Withington Hospital, Manchester; \\ and Regional Physics Department, Christie Hospital, Manchester
}

SUMMARY Body potassium status of patients with cardiac failure may be estimated by a number 0 methods, but increasing reliance is being placed upon radioisotope dilution with ${ }^{42} \mathrm{~K}$ which measures the total exchangeable potassium. Total exchangeable potassium comprises between 86 per cent and 97 per cent of whole body potassium in healthy subjects. We have measured total exchangeable potassium in 22 oedema-free elderly patients with stable cardiac failure and compared the results with simultaneously determined measurements of whole body potassium obtained by whole body counting. The mean whole body potassium was $2360 \pm 640 \mathrm{mmol}$. The mean value of total exchangeable potassium measured at 24 hours was $1820 \pm 610 \mathrm{mmol}(77 \%$ of whole body potassium) and increased further to $2000 \pm 600 \mathrm{mmol}(84 \%)$ when measured after 48 hours. In patients with cardiac failure and, perhaps, also other patients with a history of fluid retention, the mixing of a tracer dose may be significantly delayed, which if not appreciated may lead to an overestimate of potassium depletion.

A number of studies (White et al., 1969; Davidson and Gillebrand, 1973; Nicholls et al., 1976) reported in the past decade have suggested that potassium depletion is common in patients with cardiac failure. A recent review (British Medical fournal, 1977) emphasised that elderly patients should be considered to be especially at risk because of poor dietary intake of potassium, and concluded that potassium supplementation is mandatory for elderly patients in heart failure, particularly those taking long-term diuretics. In all these studies body potassium status has been estimated from measurements of the total exchangeable potassium obtained by radioisotope dilution using ${ }^{42} \mathrm{~K}$ or ${ }^{43} \mathrm{~K}$. These studies have suggested an average deficit of potassium content in cardiac failure of approximately 30 per cent. The reference values (especially pre-morbid, predicted, or actual body weights) used in these studies have not been uniform and it may well be that differences in estimated depletion are related to these factors. In general, the measurements are based on spot urine samples taken at hourly intervals from 24 hours after administration of the isotope. In only one case (Novak and Harrison, 1973) were samples taken as late as 36 hours. The radioisotope dilution method requires that equilibration should have occurred between the body otassium and the tracer; in healthy subjects this

Received for publication 15 June 1979 occurs in 24 hours (Corsa et al., 1950). However, since 1957 there have been a number of papers suggesting that in certain clinical conditions equilibration may be significantly delayed. O'Meara et al. (1957) suggested that this occurred in patients with fluid retention. Boddy et al. (1972b) investigated patients with chronic renal failure. By using the longer half-life isotope ${ }^{43} \mathrm{~K}$ and taking samples up to 64 hours after giving the tracer, they found that equilibration was significantly delayed. The same group of workers (Boddy et al., 1978) also found delayed equilibration in patients with chronic bronchitis. Therefore, the effect of basing an estimate of exchangeable potassium on samples taken at around 24 hours may well underestimate the true value of body potassium. Only three studies have so far been reported in which the total body potassium of patients in cardiac failure has been measured by counting ${ }^{40} \mathrm{~K}$ in a whole body counter. The deficits of body potassium content were reported as being 10 per cent by Delwaide and Rorive (1973); 5 per cent by Davidson et al. (1976); and Lawson et al. (1976) found no significant deficit.

The discrepancy in the findings using the two methods may in part be accounted for by the problem of delayed equilibration in the measurement of exchangeable potassium. To investigate this hypothesis we have measured both the whole body potassium and the exchangeable potassium in 
elderly patients with controlled cardiac failure. From the two measures of body potassium we also obtained the value of exchangeable potassium as a proportion of whole body potassium. This ratio in healthy volunteers measured at 24 hours has been reported to have an average value of 93 per cent with a range of 86 to 97 per cent (Rundo and Sagild, 1955; Talso et al., 1960; Surveyor and Hughes, 1968). Only one study has investigated this ratio in healthy elderly subjects where it was found to be 92 per cent (Lye et al., 1976).

\section{Patients and methods}

Eleven male and 11 female patients were investigated in this study. Clinically, the patients' cardiac condition was stable and antiheart failure treatment had been unchanged for a period of at least two months before our measurements. All patients were free from oedema at the time of study. Eighteen patients were taking both diuretics and digoxin, three of the 18 were taking thiazide diuretics, while the remainder were taking frusemide ( 40 to $80 \mathrm{mg}$ ); two patients were taking frusemide only; one patient was taking digoxin only, and one patient was not on specific antiheart failure treatment. All patients taking diuretics were also given potassium supplements $(7.7$ to $48.4 \mathrm{mmol} / 24 \mathrm{~h})$. Details of the patients studied are given in Table 1 .

Table 1 Details of patients studied

\begin{tabular}{lcc}
\hline & Men & Women \\
\hline Age $(\mathrm{y})$ & $74 \pm 6$ & $76 \pm 5$ \\
& $(67-85)$ & $(68-84)$ \\
Height $(\mathrm{cm})$ & $170 \pm 6$ & $150 \pm 5$ \\
& $(162-182)$ & $(141-157)$ \\
Weight $(\mathrm{kg})$ & $66 \pm 8$ & $51 \pm 10$ \\
& $(54-86)$ & $(34-69)$ \\
Fat free mass ${ }^{*}(\mathrm{~kg})$ & $52 \pm 6$ & $35 \pm 5$ \\
& $(45-66)$ & $(26-43)$ \\
\hline
\end{tabular}

Mean \pm 1 SD.

(Range)

${ }^{\star}$ Fat free mass from skinfold thickness.

Whole body potassium was measured using a Nuclear Enterprises shadow shield monitor to detect the naturally occurring $1.47 \mathrm{MeV}$ gamma rays emitted by ${ }^{40} \mathrm{~K}$. The detectors are four $\mathrm{NaI}(\mathrm{Tl})$ crystals, each $152 \times 102 \mathrm{~mm}$, two placed above and two placed below the motorised couch. The patient lay supine on the couch which then passed between the detectors, making a complete pass in both directions and the counts were accumulated for a total time of 45 minutes. Each patient was individually calibrated to take account of the attenuation of the gamma rays within the body, using the following method. The patient received an oral dose of $25 \mu \mathrm{Ci}$ of nuclide ${ }^{42} \mathrm{~K}$ in the form of the chloride (Radio-chemical Centre, PES. 1P). After 24 hours it was assumed that the geometrical distribution of the ${ }^{42} \mathrm{~K}$ was not significantly different from that of the natural ${ }^{40} \mathrm{~K}$. The patient was scanned again for eight minutes and the total counts accumulated. All urine passed during the 24 hours was collected and also counted. This count was compared with a standard comprising 10 per cent of the patient dose in the same volume as the urine sample so that the proportion of the administered dose excreted during the 24 hours could be determined. A phantom consisting of a five litre plastic bottle containing a dose of ${ }^{42} \mathrm{~K}$ identical to that administered to the patient was counted for 100 seconds. A second phantom containing a known quantity of natural potassium (Analar $\mathrm{KCl}$ ) was counted for 800 seconds. Each count was corrected by subtracting a background count measured under the same conditions as the corresponding patient or sample count. All ${ }^{42} \mathrm{~K}$ counts were corrected for radioactive decay $\left(t_{2} \frac{1}{2}=12.45 \mathrm{~h}\right)$ and the patient ${ }^{42} \mathrm{~K}$ count was corrected to the count which would have been obtained if all the dose had been retained. Then:

$$
\begin{aligned}
& \text { WBK } \mathrm{mmol}=\mathrm{Pt}^{40} \mathrm{~K} \text { count } \\
& \frac{\text { phantom } \mathrm{K} \mathrm{mmol}}{{ }^{40} \mathrm{~K} \text { phantom count }} \times \frac{{ }^{42} \mathrm{~K} \text { phantom count }}{\mathrm{Pt}^{42} \mathrm{~K} \text { count }}
\end{aligned}
$$

The coefficient of variation, which is inversely related to the patient ${ }^{40} \mathrm{~K}$ count, of the results obtained by this technique with the present apparatus had a mean value of 4.6 per cent, with a range of 3.2 to 6.7 per cent. We believe that the direct calibration method is more accurate than calculation of a calibration factor based on height and weight (Boddy et al., 1972a).

Total exchangeable potassium was measured concurrently with the whole body potassium and made use of the fact that the patient had already received a dose of ${ }^{42} \mathrm{~K}$. A urine sample was preferred to a plasma sample because of the higher potassium concentration in urine (Surveyor and Hughes, 1968); the associated higher count rate improves the accuracy of the assay. The volume was measured accurately and then the sample was counted on a single crystal of the monitor. A minimum of 2000 counts was acquired. A standard containing 10 per cent of the original dose in the same volume was also counted. All counts were corrected for background and radioactive decay. The 24-hour excreted proportion obtained in the whole body potassium measurement was used to correct the spot urine count. The concentration of potassium in the spot sample was measured by flame emission spectrophotometry using a Pye-Unicam SP 192 
atomic absorption spectrophotometer. Then:

$\mathrm{TeK}_{24} \mathrm{mmol}=$

$$
\mathrm{K} \text { content of spot urine } \times \frac{\text { Standard count } \times 10}{\text { Spot urine count }}
$$

The urine collection was continued up to $48 \pm 2$ hours from giving the oral dose at which time a further spot urine sample was taken. $\mathrm{TeK}_{48}$ was estimated from this sample in an identical manner. The coefficient of variation of the results obtained by this technique had a mean value of 2.3 per cent, with a range of 0.6 to 5.0 per cent in the case of $\mathrm{TeK}_{24}$, and a mean value of 5.4 per cent, with a range of 1.9 to 14.8 per cent in the case of $\mathrm{TeK}_{48}$. The reason for the greater coefficient of variation for the 48-hour estimate is that, because of radioactive decay, the background count forms a higher proportion of the total count.

The patients were all in hospital at the time of the study and the urine collections were supervised by a research nurse. Patients with incontinence or intermittent confusion were excluded. We are therefore satisfied that most urine collections were complete. In the known cases of incomplete collection, an average value of 96.3 per cent retention was assumed.

\section{Results}

The data obtained from the 22 patients are shown in Table 2. The mean whole body potassium of all patients was $2360 \pm 640 \mathrm{mmol}$ and ranged from 1350 to $3640 \mathrm{mmol}$. The ratio of total exchangeable potassium to whole body potassium had a mean value of $77 \pm 13$ per cent with a range of 32 to 100 per cent at 24 hours and $85 \pm 10$ per cent with a range of 66 to 106 per cent at 48 hours.

In eight of the 11 men and nine of the 11 women, $\mathrm{TeK}_{48}$ was higher than $\mathrm{TeK}_{24}$. In one of the men there was no change in total exchangeable potassium and in two patients of each sex, $\mathrm{TeK}_{48}$ was actually lower than $\mathrm{TeK}_{24}$. However, the mean change in total exchangeable potassium shows an increase from 24 to 48 hours for each sex. The pooled data for both sexes show that the mean increase in total exchangeable potassium is $170 \pm 310 \mathrm{mmol}$. Similarly, the mean increase in the ratio of total exchangeable potassium to whole body potassium is $8 \pm 14$ per cent. In both cases the increase is significant $(t=2 \cdot 6, \mathrm{P}<0 \cdot 01)$. $\mathrm{TeK}_{24}$ and $\mathrm{TeK}_{48}$ are plotted against whole body potassium in the Fig. There is a higher correlation $(r=0.94)$ between $\mathrm{TeK}_{48}$ and whole body potassium than between $\mathrm{TeK}_{24}$ and whole body potassium $(\mathrm{r}=0.86)$.

A number of patients, not unexpectedly in view of their chronic cardiac failure, had evidence of impaired renal function. The mean blood urea was $8 \pm 5 \mathrm{mmol} / \mathrm{l}$, with a range of 5 to $23 \mathrm{mmol} / \mathrm{l}$. There were five patients (three women) whose blood urea was $10 \mathrm{mmol} / \mathrm{l}$ or more. The mean creatinine clearance was $56 \pm 37 \mathrm{ml} / \mathrm{min}$ with a

Table 2 Individual values of whole body potassium (WBK), exchangeable potassium measured at 24 hours ( $\left(\mathrm{T}_{24}\right.$ ) and at 48 hours $\left(T e K_{48}\right)$, and derived variables

\begin{tabular}{|c|c|c|c|c|c|c|c|}
\hline & $\begin{array}{l}\text { WBK } \\
\text { (mmol) }\end{array}$ & $\begin{array}{l}T e K_{24} \\
(m m o l)\end{array}$ & $\begin{array}{l}T e K_{48} \\
(m m o l)\end{array}$ & $\begin{array}{l}\Delta T e K \\
(m m o l)\end{array}$ & $\begin{array}{l}T e K_{24} / \\
W B K(\%)\end{array}$ & $\begin{array}{l}T e K_{48} / \\
W B K(\%)\end{array}$ & $\begin{array}{l}\Delta T e K \\
W B K(\%)\end{array}$ \\
\hline $\begin{array}{l}\text { Men } \\
\text { Mean } \\
\text { SD } \\
\text { Women } \\
\text { Wean } \\
\text { SD } \\
\text { Pooled mean } \\
\text { SD }\end{array}$ & $\begin{array}{r}2060 \\
2860 \\
2840 \\
2350 \\
3330 \\
2510 \\
3240 \\
2880 \\
3120 \\
2520 \\
3640 \\
2850 \\
470 \\
1350 \\
1810 \\
1730 \\
1600 \\
1660 \\
2010 \\
1730 \\
2590 \\
2200 \\
2150 \\
1810 \\
1880 \\
340 \\
2360 \\
640\end{array}$ & $\begin{array}{r}1660 \\
2360 \\
2080 \\
750 \\
2670 \\
1530 \\
2350 \\
2890 \\
2640 \\
2000 \\
2940 \\
2170 \\
660 \\
1040 \\
1470 \\
1230 \\
1150 \\
1300 \\
1510 \\
1540 \\
1950 \\
1910 \\
1490 \\
1620 \\
1470 \\
290 \\
1820 \\
610\end{array}$ & $\begin{array}{r}1360 \\
2500 \\
2220 \\
1640 \\
2830 \\
2120 \\
2620 \\
2450 \\
2640 \\
2270 \\
3500 \\
2380 \\
570 \\
1140 \\
1560 \\
1420 \\
1330 \\
1720 \\
1840 \\
1830 \\
2360 \\
1680 \\
1600 \\
1310 \\
1620 \\
330 \\
2000 \\
600\end{array}$ & $\begin{array}{r}-300 \\
140 \\
140 \\
880 \\
165 \\
590 \\
280 \\
-440 \\
0 \\
260 \\
560 \\
210 \\
380 \\
100 \\
88 \\
190 \\
180 \\
420 \\
330 \\
290 \\
410 \\
-230 \\
110 \\
-310 \\
140 \\
240 \\
170 \\
310\end{array}$ & $\begin{array}{r}81 \\
83 \\
73 \\
32 \\
80 \\
61 \\
73 \\
100 \\
85 \\
80 \\
81 \\
75 \\
17 \\
77 \\
81 \\
71 \\
72 \\
79 \\
75 \\
89 \\
76 \\
87 \\
69 \\
90 \\
79 \\
7 \\
77 \\
13\end{array}$ & $\begin{array}{r}66 \\
87 \\
78 \\
70 \\
85 \\
84 \\
81 \\
85 \\
85 \\
90 \\
96 \\
83 \\
9 \\
85 \\
86 \\
83 \\
83 \\
104 \\
91 \\
106 \\
91 \\
76 \\
74 \\
73 \\
87 \\
11 \\
84 \\
10\end{array}$ & $\begin{array}{r}-15 \\
4 \\
5 \\
38 \\
5 \\
13 \\
8 \\
-15 \\
0 \\
10 \\
15 \\
7 \\
15 \\
8 \\
5 \\
12 \\
11 \\
25 \\
16 \\
17 \\
15 \\
-11 \\
5 \\
-17 \\
8 \\
12 \\
8 \\
14\end{array}$ \\
\hline
\end{tabular}




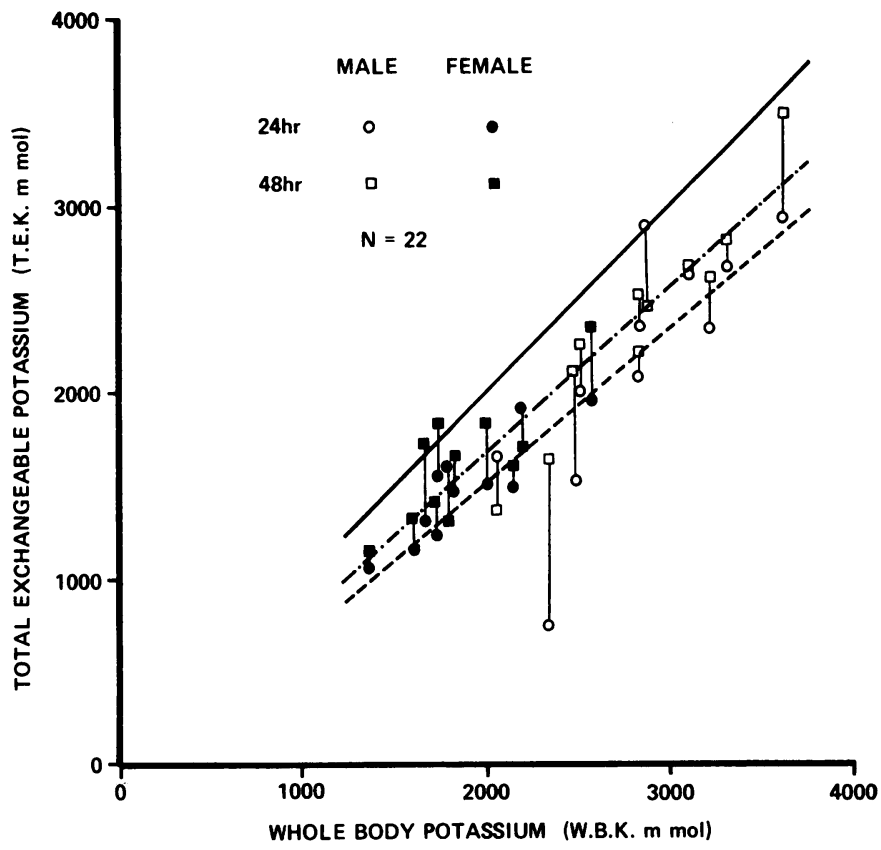

Fig. Relation of whole body potassium (WBK) to total exchangeable potassium measured at 24 hours --.-- $\left(\mathrm{TeK}_{24}\right)$, and at 48 hours -.-.' $\left(\mathrm{TeK}_{48}\right)$. range from 7 to $116 \mathrm{ml} / \mathrm{min}$. Six patients had a creatinine clearance below $20 \mathrm{ml} / \mathrm{min}$ and two patients had values below $10 \mathrm{ml} / \mathrm{min}$. The ratios $\mathrm{TeK}_{24} / \mathrm{WBK}$ and $\mathrm{TeK}_{48} / \mathrm{WBK}$ did not significantly correlate $(P>0.05)$ with the blood urea $(r=0.03$ and 0.38 , respectively) or with the creatinine clearance $(r=0.01$ and 0.27 , respectively).

\section{Discussion}

Our results give a value of 77 per cent at 24 hours and 84 per cent at 48 hours for the ratio of total exchangeable potassium to whole body potassium, compared with an average normal value of 93 per cent reported previously. The only methodological factor which could affect the results was the completeness of the 24-hour urine collections. However, an incomplete urine collection would lead to an over-estimate of both total exchangeable potassium and whole body potassium and would, therefore, not affect the ratio. It is possible that either the proportion of whole body potassium which is exchangeable is reduced in patients with cardiac failure, or that a value within the normal range would have been obtained had measurements been extended beyond 48 hours. Because we have only two measurements for each patient, it is not possible to distinguish between these possibilities.

Boddy et al. (1972b) found that the ratio of total exchangeable potassium to whole body potassium was significantly reduced in patients with chronic renal failure, that is patients in whom creatinine clearance is less than $10 \mathrm{ml} / \mathrm{min}$. However, the present study shows no correlation between completeness of equilibration at 24 or 48 hours and indices of renal function. It is perhaps interesting to note that the patients with chronic bronchitis studied by Boddy et al. (1978) had all experienced one or more episodes of fluid retention, but at the time of study they were, as were our patients, free from oedema.

The fact that total exchangeable potassium increased significantly during the second 24-hour period leads us to believe that equilibration times are increased in the present group of subjects and confirms the findings of earlier reports on patients with cardiac failure. Where body potassium has been estimated from measurements of total exchangeable potassium, it has been suggested that body potassium is significantly reduced (Davidson and Gillebrand, 1973; Nicholls et al., 1976; British Medical fournal, 1977). However, where whole body potassium has been measured by whole body counting, little or no deficit has been found (Delwaide and Rorive, 1973; Davidson et al., 1976; Lawson et al., 1976). The present study confirms that, for patients with cardiac failure, the quantification of the degree of potassium depletion by measuring total exchangeable potassium may well exaggerate the degree of depletion, and caution should be exercised in basing any treatment regimen on such tests. 
This work was generously supported by the Scientific Committee of the North Western Regional Health Authority.

\section{References}

Boddy, K., Davies, D. L., Howie, A. D., Madkour, M. M., Mahaffy, M. E., and Pack, A. I. (1978). Total body and exchangeable potassium in chronic airways obstruction: a controversial area? Thorax, 33, 62-66.

Boddy, K., King, P. C., Hume, R., and Weyers, E. (1972a). The relation of total body potassium to height, weight and age in normal adults. Fournal of Clinical Pathology, 25, 512-517.

Boddy, K., King, P. C., Lindsay, R. M., Winchester, J., and Kennedy, A. C. (1972b). Exchangeable and total body potassium in patients with chronic renal failure. British Medical fournal, 1, 140-142.

British Medical fournal (1977). Potassium in heart failure. 1, 469-470.

Corsa, L., Olney, J. M., Steenburg, R. W., Ball, M. R., and Moore, F. D. (1950). The measurement of exchangeable potassium in man by isotope dilution. fournal of Clinical Investigation, 29, 1280-1295.

Davidson, C., Burkinshaw, L., McLachlan, M. S. F., and Morgan, D. B. (1976). Effect of long-term diuretic treatment on body potassium in heart disease. Lancet, 2, 1044-1047.

Davidson, C., and Gillebrand, I. M. (1973). Use of amiloride as a potassium conserving agent in severe cardiac disease. British Heart fournal, 35, 456-461.

Delwaide, P. A., and Rorive, G. L. (1973). Intérêt de la determination du potassium total en cardiologie. Acta Cardiologica, 17, Suppl., 282-290.

Lawson, D. H., Boddy, K., Gray, J. M. B., Mahaffy, M. E., and Mills, E. (1976). Potassium supplements in patients receiving long-term diuretics for oedema. Quarterly fournal of Medicine, 45, 469-478.
Lye, M., May, T., Hammick, J., and Ackery, D. (1976). Whole body and exchangeable potassium measurements in normal elderly subjects. European fournal of Nuclear Medicine, 1, 167-171.

Nicholls, M. G., Espiner, E. A., Hughes, H., and Rogers, T. (1976). Effects of potassium sparing diuretics on the renin-angiotensin aldosterone system and potassium retention in heart failure. British Heart fournal, 38, 1025-1030.

Novak, L. P., and Harrison, C. E. (1973). Abnormalities of cellular potassium concentration in uncompensated and compensated congestive heart failure. Mayo Clinic Proceedings, 48, 107-113.

O'Meara, M. P., Birkenfeld, L. W., Gotch, F. A., and Edelman, I. S. (1957). The equilibration of radiosodium ( $\mathrm{Na} 24)$, radio-potassium (K42), and deuterium oxide (D20) in hydropic human subjects. fournal of Clinical Investigation, 36, 784-792.

Rundo, J., and Sagild, U. (1955). Total and 'exchangeable' potassium in humans. Nature, 175, 774.

Surveyor, I., and Hughes, D. (1968). Discrepancies between whole body potassium content and exchangeable potassium. Fournal of Laboratory and Clinical Medicine, 71, 464-472.

Talso, P. J., Miller, C. E., Carballo, A. J., and Vasquez, I. (1960). Exchangeable potassium as a parameter of body composition. Metabolism, 9, 456-471.

White, R. J., Chamberlain, D. A., Hamer, J., McAlister, J., and Hawkins, L. A. (1969). Potassium depletion in severe heart disease. British Medical fournal, 2, 606-610.

Requests for reprints to Dr Michael Lye, Department of Geriatric Medicine, University of Manchester, Withington Hospital, Manchester M20 8LR. 